\title{
A Note on Intrinsic Inflation Persistence and the Optimal Inflation Rate
}

\author{
Dario Pontiggia
}

Neapolis University Pafos, 2 Danais Avenue, 8042, Pafos, Cyprus

Abstract: This paper examines the implications of intrinsic inflation persistence, namely inertia that inflation inherits from its own past, on the conduct of optimal monetary policy. We study the optimal long-run rate of inflation in a basic New Keynesian model, which is augmented for intrinsic inflation persistence. We show that the commitment solution for the monetary authority leads to steady-state outcomes in which inflation is positive.

Keywords: Optimal monetary policy, Phillips curve, inflation persistence.

\section{INTRODUCTION}

What constitutes the optimal long-run (or steadystate) rate of inflation, OLIR for short, is a central issue in monetary economics. Central banks have chosen modestly positive, near two percent, steady-state inflation rates. Indeed, the recent global economic crisis has prompted a policy debate around the opportunity for central banks to revisit upward their inflation targets. For instance, Blanchard, Dell'Ariccia and Mauro (2010) and Ball (2013) argue that central bankers should consider aiming for a higher OLIR than they do currently to lessen the chances of repeating the recent Great Recession. Theoretical reasons for the OLIR are often linked to the Fisher identity, which states that the nominal interest rate is equal to the real interest rate plus expected inflation. On the one hand, Friedman (1969) advocates setting the nominal interest rate to zero so to eliminate shoe-leather costs involved in economizing on money balances: the monetary authority should accordingly pursue a deflation equal to the real interest rate. On the other hand, several economists (e.g. Summers 1991; Krugman 1998;Svensson 2003) argue in favour of a low and positive OLIR so to avoid the zero-lower bound on the nominal interest rate and thus guarantee enough room to ease monetary policy in response to economic downturns. Moreover, there are other reasons for having a low but positive OLIR. First, as argued by Tobin (1972), modestly positive inflation may grease the wheel of the labour market. If nominal wages are downwardly rigid, a little inflation can allow firms to lower real wages and maintain employment in response to contracting demand. Second, as

*Address correspondence to this author at the Neapolis University Pafos, 2 Danais Avenue, 8042, Pafos, Cyprus; Tel: + 35726843 411;

E-mail: d.pontiggia@nup.ac.cy

JEL Classification: E31, E32, E52. conjectured by Fisher (1933), deflation can be more costly than inflation as it may trigger a debt-deflation spiral. When the nominal value of assets purchased with debt declines, the real burden of debt rises and this can cause financial turmoil through high rates of default and force asset sales, thus putting further downward pressure on prices. Third, measures of inflation tend to be biased upward. Given the central bank's preferred measure of inflation, targeting zero steady-state inflation would imply a deflation equal to the upward bias.

Economists have used a variety of economic models to estimate the central bank's OLIR. These models share a common trait: given the monetary authority's inflation and output objectives and subject to the frictions in the economic environment, the OLIR is the inflation rate that achieves the best economic performance. Earlier models of determination of the inflation target assumed the monetary authority's inflation and output objectives. Today, the general equilibrium nature of the so-called New Keynesian (NK) models allows founding the central bank's objective function upon the utility function of the representative household.

NK models are characterized by two central components: forward-looking expectations with intertemporal optimization and imperfect competition with nominal rigidities. Nominal rigidities are commonly modelled in terms of a constraint on the frequency of price setting. Firms optimally re-setting their prices thus internalize the probability that those prices will remain effective for more than one period. Such pricing decisions anticipate the future and imply that inflation is a purely forward-looking phenomenon. This property is clearly reflected in the New Keynesian Phillips Curve (NKPC). While the NKPC is a building block of the workhorse NK model, many economists doubt that is a 
reliable tool for monetary policy analysis. This is because it cannot match the observed behaviour of inflation, and, in particular, it cannot deliver inflation persistence (e.g. Fuhrer and Moore 1995) and thus justify the costs of disinflation (e.g. Ball 1994). Moreover, the standard NK model is often criticized for its lack of a trade-off between inflation and output gap stabilization and the strict normative implications that arise from it. Zero OLIR is optimal and this is despite the inefficiency of the deterministic steady state and despite the existence of a long-run Phillips-curve tradeoff, as implied by the NKPC.

Economists have thus put forward a number of extensions to the standard NK framework by incorporating potential sources of intrinsic inflation persistence, namely inertia that inflation inherits from its own past. Recently, Fuhrer (2010), in a comprehensive survey of a large body of research on inflation persistence, concludes that the largest changes in inflation persistence are most likely due to changes in the intrinsic sources of inflation persistence.

In this note, we study the implications of intrinsic inflation persistence for the OLIR. We look at solutions assuming commitment on the part of the monetary authority. We take no stance on the source of intrinsic inflation persistence, but simply consider the augmented Phillips curve that allows for intrinsic inflation persistence analysed in Fuhrer (2010). As a result, we do not analyse steady-state inflation in a fully microfounded set-up. On the one hand, the setting we employ can be interpreted as the basic NK model, characterized by monopolistic competition in product markets and Calvo (1983) price staggering, which is augmented for intrinsic inflation persistence. On the other hand, the framework we consider could also be interpreted as a standard Barro-Gordon model (1983) where the New Classical Phillips curve is replaced by a hybrid, namely partially backward-looking, Phillips curve.

We show that the commitment solution leads to steady-state outcomes in which the monetary authority targets a positive rate of inflation. If optimal monetary policy under commitment should target zero OLIR in a basic NK model, despite steady-state distortions and the existence of a positively sloped long-run Phillips curve, zero long-run inflation ceases to be optimal once the Phillips curve allows for intrinsic inflation persistence. Intrinsic inflation persistence generates a long-run incentive for positive inflation. The long-run Phillips-curve trade-off, which would equally obtain under the purely forward-looking NKPC, is then exploited, resulting in a positive inflation target under commitment. In particular, the positive OLIR depends on the model's structural parameters and nests zero as a special case.

The remainder of the paper is organized as follows. Section 2 spells out the model economy. Section 3 contains the main results and Section 4 concludes.

\section{THE MODEL}

The model of central bank behaviour consists of the Phillips curve, namely the aggregate-supply relationship, and the policy objective function. The aggregate-demand relationship does not impose a real constraint on the central bank. This is because, as in theoretical literature on optimal monetary policy, the monetary authority is assumed to control the short-term nominal interest rate. Solving the model of central bank's behaviour delivers the equilibrium paths for inflation and output gap. Given equilibrium paths for inflation and output gap, the aggregate-demand relationship then determines the setting for the nominal interest rates, which must always be nonnegative. ${ }^{1}$

The monetary authority minimizes a quadratic discounted loss,

$L=\frac{1}{2} E_{t} \sum_{t=0}^{\infty} \beta^{t}\left[\pi_{t}^{2}+\lambda\left(x_{t}-x^{*}\right)^{2}\right]$

where $E_{t}$ denotes the expectations operator conditional on information available at time $\mathrm{t}, \beta$ is the subjective discount factor, and $\lambda>0$ is the relative weight placed on output gap stabilization. On the one hand, equation (1) resembles the standard quadratic loss function employed in earlier literature (e.g. Kydland and Prescott 1977, Barro and Gordon 1983) to represent the objectives of the monetary policy authority. On the other hand, Woodford (2003) has shown how the quadratic discounted loss in (1) can be derived as a second-order approximation to the welfare of the representative household in the basic NK model, which features one nominal rigidity (i.e. sticky prices) and one real rigidity (i.e. imperfect competition). Indeed, the microfoundations of the policy objective function bring about two crucial differences with respect with its earlier non-microfounded counterpart.

\footnotetext{
${ }^{1}$ This is always true in our analysis. Indeed, in the presence of intrinsic inflation persistence, the optimality of positive steady-state values for the inflation rate, hence the output gap, implies that the nominal interest rate is also positive at steady state.
} 
First, output and output gap concepts are more firmly grounded in theory. The efficient level of output is the level of output that would prevail in the absence of both real and nominal rigidities whereas the natural level of output is the level of output that would prevail in the absence of nominal rigidities. Accordingly, while the output gap, $x_{t}$, is the distance between the actual level of output and the natural level of output, the welfarerelevant output gap is the distance between the actual level of output and the efficient level of output. The objective function in fact implies that the central bank's output target, namely the efficient level of output, is above the natural rate of output because of distortions caused by monopolistic competition (i.e. $x^{*}>0$ ). Specifically, the divine coincidence perceived by Blanchard and Galì (2007) holds as the gap between the natural level of output and the efficient level of output is constant and invariant to shocks.

Second, inflation, $\pi_{t}$, matters for welfare because of sticky prices. Given nominal rigidities in price setting, welfare considerations call for stabilization of the degree of price dispersion. Price dispersion reduces utility as a result of diminishing marginal utility: the increase in utility that the representative household derives from consuming more of the relatively cheaper goods is less than the loss in utility caused by having to consume less of the relatively more expensive goods. The details of the price setting in turn relate the degree of price dispersion to variations in the aggregate price level.

We take no stance on the source of intrinsic inflation persistence and consider the augmented Phillips curve that allows for intrinsic inflation persistence analysed in Fuhrer (2010). The inflation rate and the output gap in any period accordingly satisfy

$$
\pi_{t}=(\beta-\mu) E_{t} \pi_{t+1}+\mu \pi_{t-1}+k x_{t}
$$

The coefficient $\mu$ measures the degree of intrinsic inflation persistence and $k>0$ is the output gap coefficient. ${ }^{2}$ The hybrid Phillips curve can easily be interpreted as the purely forward-looking NKPC, namely $\pi_{t}=\beta E_{t} \pi_{t+1}+k x_{t}$, to which lagged inflation is attached. The hybrid Phillips curve implies a steep upward-sloping relation, that is $\bar{\pi}=[\kappa /(1-\beta) \bar{x}$, between steady-state inflation, $\bar{\pi}$, and the steady-state output gap, $\bar{x}$. It is important to stress that the long-run

\footnotetext{
${ }^{2}$ We treat $\mu$ and $\kappa$ as structural parameters whereas in a fully-microfounded model they would be function of underlying deep parameters.
}

Phillips-curve trade-off takes the same form of the one implied by the purely forward-looking NKPC. Accordingly, the long-run Phillips curve would become vertical only if the monetary authority were not to discount the future (i.e. $\beta=1$ ).

Considering a specific source of intrinsic inflation persistence would affect the details of the price setting, which would then result in changes to the central bank's welfare-based objective and the Phillips curve. Indeed, in order to accommodate the observed persistence in inflation data, two main variants of the standard NK model have been proposed in the literature: rule-of-thumb price setters (Galì and Gertler 1999) and indexation to lagged inflation (Christiano, Eichenbaum and Evans 2005). Within a fully microfounded general equilibrium model, Woodford (2003) studies the implications of indexation to lagged inflation on the OLIR while Pontiggia (2012) analyses them in the presence of rule-of-thumb behaviour. A comparison between those results provides an example of the macroeconomic equivalence and microeconomic dissonance emphasized in Levin et al. (2008). The two variants of the Calvo model yield hybrid Phillips curves that are first-order equivalent, but they imply different optimal long-run inflation rates: positive under rule-of-thumb behaviour and zero under backward-looking price indexation. Conversely, our analysis can be interpreted as a generalization of the results in Pontiggia (2012). This is because of two reasons. First, the hybrid Phillips curve in (2) and its counterpart under Galì-Gertler's rule-of-thumb behaviour by price setters are not only observationally equivalent but also share the same long-run Phillipscurve trade-off, namely the one implied by the NKPC. Second, under Galì-Gertler's rule-of-thumb behaviour by price setters the welfare-based objective function would include an additional term in inflation acceleration, $\pi_{t}-\pi_{t-1}$, which would not matter for the determination of the optimal steady-state inflation rate.

\section{MONETARY POLICY}

In this section, we study the optimal long-run rate of inflation in a purely deterministic setting, certainty equivalence guarantees that the results we obtain hold in the presence of random disturbances. The monetary authority is assumed to be able to act under commitment. ${ }^{3}$ The analysis of the OLIR under commitment takes the form of a constrained

${ }^{3}$ Discretionary conduct of monetary policy would result in the well-known inflation bias, as first stressed by Kydland and Prescott (1977). 
optimization problem. The monetary authority chooses bounded paths for inflation and the output gap, $\left\{\pi_{t}, x_{t}\right\}_{t=0}^{\infty}$, to minimize the quadratic discounted loss (1) subject to the constraint that the sequences satisfy the hybrid Phillips curve (2) each period. We form the following Lagrangian

$\digamma=\sum_{t=0}^{\infty} \beta^{t}\left\{\begin{array}{l}\frac{1}{2}\left[\pi_{t}^{2}+\lambda\left(x_{t}-x^{*}\right)^{2}\right]+ \\ v_{t}\left[\pi_{t}-(\beta-\mu) E_{t} \pi_{t+1}-\mu \pi_{t-1}-\kappa x_{t}\right]\end{array}\right\}$

where $v_{t}$ is the Lagrange multiplier associated with the t-period aggregate-supply relation. Differentiation of the Lagrangian with respect to inflation and output gap, yields a pair of first-order conditions

$\pi_{t}+v_{t}-\beta^{1-}(\beta-\mu) v_{t-1}-\beta \mu v_{t+1}=0$

$\lambda\left(x_{t}-x^{*}\right)-\kappa v_{t}=0$

It must be stressed that the OLIR does not depend on the form of commitment policy. Under the standard (i.e. zero-optimal) commitment policy, the inflation optimality condition in the initial period differs from that applying to all later periods (i.e. $v_{-1}=0$ in (4) for $t=0$ ). As a result, the zero-optimal commitment policy is time inconsistent. An alternative definition of commitment policy solves the time inconsistency of the zero-optimal policy by requiring that the central bank implements both optimality conditions (4) and (5) for all periods, including the initial period. Woodford (1999) has labelled this the timeless perspective commitment policy. The different time structure for the optimality conditions does not in fact affect the determination of the steady-state inflation rate. ${ }^{4}$ Without loss of generality, we therefore consider timeless-perspective commitment policy. Formally, the definition of the OLIR is the same as in Woodford (2003, p. 475): a constant inflation target $\bar{\pi}$ is optimal from a timeless perspective if the problem of minimizing (1) subject to the constraint that the bounded sequences, $\left\{\pi_{t}, x_{t}\right\}_{t=0}^{\infty}$, satisfy (2) for each $t \geq 0$, and the additional constraint that $\pi_{0}=\bar{\pi}$, has a solution in which $\pi_{t}=\bar{\pi}$ for all $t$.

Condition (1) has a solution with inflation constant over time only if the Lagrange multiplier is also constant over time. The two optimality conditions can be simultaneously satisfied only if

$\bar{\pi}=\frac{\lambda \mu\left(1-\beta^{2}\right)}{\beta \kappa}(x *-\bar{x})$

${ }^{4}$ It would matter for the economy's dynamic paths toward its steady-state levels.
Combining this with the long-run Phillips curve trade-off yields the optimal long-run inflation target

$\bar{\pi}=\frac{\lambda \mu \kappa\left(1-\beta^{2}\right)}{\beta \kappa^{2}+\lambda \mu(1-\beta)\left(1-\beta^{2}\right)} x *$

Given $\lambda>0$ and $\kappa>0$, optimal long-run inflation under commitment is positive and collapses to zero in the absence of intrinsic inflation persistence (i.e. $\mu=0$ ), in the absence of steady-state distortions (i.e. $\left.x^{*}=0\right)$, and in the presence of a vertical long-run Phillips curve (i.e. $\beta=1$ ).

The optimal long-run rate of inflation in (6) depends on the model's five unknown parameters: $\beta, \kappa, \lambda, \mu$ and $x *$. We proceed to calibrate the model where the time period is one quarter. Table 1 summarizes the calibration.

Table 1: Calibration (Quarterly)

\begin{tabular}{|c|c|}
\hline Parameter Definition & Value \\
\hline \hline Subjective discount factor & $\beta=0$ \\
\hline Degree of intrinsic inflation persistence & $0 \leq \mu \leq 0.9$ \\
\hline Weight on output gap stabilization & $\lambda=0.25$ \\
\hline Output gap coefficient & $\kappa=0.05$ \\
\hline Efficient level of the output gap & $x^{*}=0.2$ \\
\hline
\end{tabular}

The values for three structural parameters $\beta, \kappa, \lambda$ are taken from Walsh (2010). In calibrating the efficient level of the output gap, $x *$, we follow Woodford (2003) and accordingly set it equal to 0.2 . As for the degree of intrinsic inflation persistence, the uncertainty surrounding the importance of future inflation vis-à-vis lagged inflation in a hybrid Phillips curve is well-known. We thus follow Fuhrer (2010) and consider values of $\mu$ ranging from 0 to 0.9 . If the objective function (1) were to be derived as an approximation to the welfare of the representative agent, the implied value for the weight on output gap stabilization would be smaller than our benchmark value. In quantifying the long-run inflation rate, we also consider different and lower values for $\lambda$. Figure 1 shows the size of the optimal steady-state inflation rate in annualized percentage terms. Starting from zero under the NKPC, the OLIR is seen to rise monotonically with the degree of intrinsic inflation persistence. $^{5}$

${ }^{5}$ Comparative statics show that the optimal long-run inflation target is strictly increasing in $\lambda, \mu$ and $x *$ and non-monotonic in $\beta$ and $\kappa$ 


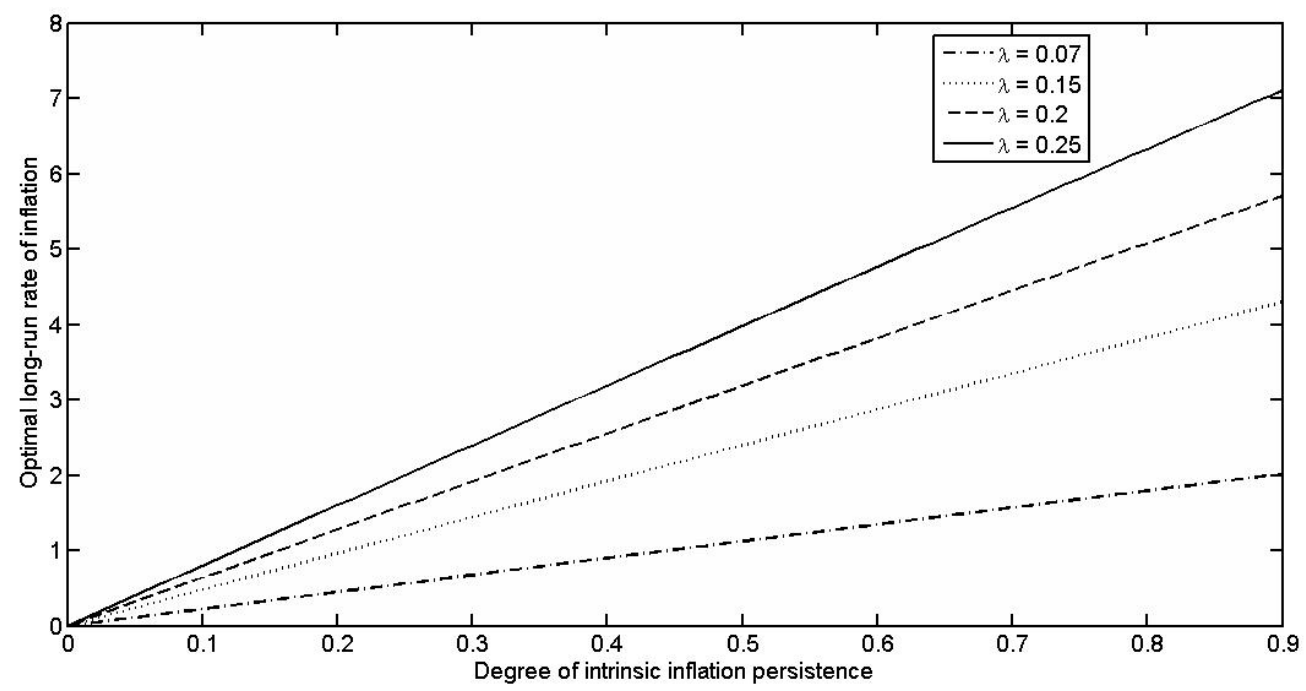

Figure 1: Optimal long-run inflation target in percentage points (y-axis) for varying degrees of intrinsic inflation persistence (x-axis) and selected weights on output gap stabilization.

The existence of an inefficient natural level of output $\left(x^{*}>0\right)$ coupled with a long-run Phillips-curve trade-off $(\beta<1)$ could imply that the Phillips curve is exploited, thus resulting in positive inflation at steady-state, even under commitment. However, this is not the case in the basic NK model, where it is optimal to commit to zero inflation. As discussed in Woodford (2003), zero OLIR arises as there is no long-run incentive for nonzero inflation under an optimal commitment. The NKPC entails that higher inflation in any period has an output benefit as it increases output in the same period, but also an output cost as it decreases output in the previous period as a result of the anticipation of that higher inflation. On the one hand, expected future inflation carries a smaller coefficient (i.e $\beta<1$ ) relative to the coefficient on current inflation (i.e. 1), which gives rise to the upward-sloping long-run Phillips curve. On the other hand, the output cost of higher future inflation is weighted more strongly as it occurs earlier in time. Indeed, the output cost of higher anticipated inflation exactly offsets the stimulative effect of higher current inflation. ${ }^{6}$ As a result, there is no long-run incentive for nonzero inflation under an optimal commitment.

Intrinsic inflation persistence, $\mu>0$, generates a long-run incentive for positive inflation under commitment. Given the hybrid nature of the Phillips curve in (2), higher inflation in any period increases

${ }^{6}$ This can easily be seen by setting $\mu=0$ in the inflation optimality condition (4), namely $\pi_{t}+v_{t}+v_{t-1}=0$. output in the same period, but decreases output both in the previous period as a result of the anticipation of that higher inflation and in the subsequent period as a result of the realization of that higher inflation. From the standpoint of the discounted objective function, as given by the inflation optimality condition (4), the stimulative effect of higher current inflation on output is greater or equal than the output cost of higher, both anticipated and realized, inflation if and only if

$v_{t}-\beta^{-1}(\beta-\mu) v_{t-1}-\beta \mu v_{t+1} \geq 0 \rightarrow \mu\left(\frac{1-\beta^{2}}{\beta}\right) \geq 0$

The inequality in (7) substantiates the positive and monotonic relationship between the OLIR and the degree of intrinsic inflation persistence, as depicted in Figure 1. Moreover, in the presence of a vertical longrun Phillips curve (i.e. $\beta=1$ ), intrinsic inflation persistence implies a zero steady-state inflation under commitment. In the standard NK model, a vertical longrun Phillips curve would instead imply a negative OLIR (e.g. Woodford 2003 Ch. 6) as the stimulative effect of higher inflation would be judged to be worth less than the output cost of higher anticipated inflation.

\section{CONCLUSIONS}

The contribution we make in this note is to analyse the optimal, under commitment, long-run inflation target in the presence of intrinsic inflation persistence. In so doing, we take no stance on the source of intrinsic inflation persistence, but consider a hybrid, namely partially backward-looking, Phillips curve. Consequently, the analysis is not conducted in a fully- 
microfounded set-up. On the one hand, the model we employ can be interpreted as the basic NK model augmented for intrinsic inflation persistence. On the other hand, the framework we consider could also be interpreted as a standard Barro-Gordon model (1983) where the New Classical Phillips curve is replaced by a hybrid Phillips curve.

We show that the monetary authority commits to a positive long-run inflation rate in the presence of intrinsic inflation persistence. If optimal monetary policy under commitment should target zero OLIR in a basic NK model, despite steady-state distortions and the existence of a positively sloped long-run Phillips-curve, zero long-run inflation ceases to be optimal once the Phillips curve allows for intrinsic inflation persistence. Intrinsic inflation persistence generates a long-run incentive for positive inflation. The long-run Phillipscurve trade-off, which would equally obtain under the purely forward-looking NKPC, is then exploited, resulting in a positive inflation target under commitment.

\section{REFERENCES}

Barro, Robert J. and David B. Gordon. 1983. "A Positive Theory of Monetary Policy in a Natural Rate Model." Journal of Political Economy 91:589-610. http://dx.doi.org/10.1086/261167

Ball, Laurence M. 2013. "The Case for Four Percent Inflation." Central Bank Review 13:17-31.

Ball, Laurence M. 1994. "Credible Disinflation with Staggered Price Setting." American Economic Review 84:282-289.

Blanchard, Olivier, Giovanni Dell'Ariccia and Paolo Mauro. 2010. "Rethinking Macroeconomic Policy." Journal of Money, Credit, and Banking 42:199-215. http://dx.doi.org/10.1111/j.1538-4616.2010.00334.x

Blanchard, Olivier and Jordi Galí. 2007. "Real Wage Rigidities and the New Keynesian Model." Journal of Money, Credit, and Banking 39:35-65.

http://dx.doi.org/10.1111/j.1538-4616.2007.00015.x

Calvo, Guillermo A. 1983. "Staggered Prices in a Utility-Maximising Framework." Journal of Monetary Economics 12:383-398. http://dx.doi.org/10.1016/0304-3932(83)90060-0

Christiano, Lawrence M., and Martin Eichenbaum and Charles L. Evans. 2005. "Nominal Rigidities and the Dynamic Effects of a Shock to Monetary Policy." Journal of Political Economy 113:1-45 http://dx.doi.org/10.1086/426038
Fisher, Irving. 1933. "The Debt-Deflation Theory of Great Depressions." Econometrica 1:337-357. http://dx.doi.org/10.2307/1907327

Fuhrer, Jeffrey C. 2010. "Inflation Persistence" Pp. 423-486 in Handbook of Monetary Economics, edited by B. Friedman and M. Woodford. Elsevier. http://dx.doi.org/10.1016/b978-0-444-53238-1.00009-0

Fuhrer, Jeffrey C. and George Moore. 1995. "Inflation Persistence." Quarterly Journal of Economics 110:127-159. http://dx.doi.org/10.2307/2118513

Friedman, Milton. 1969. "The Optimum Quantity of Money." Pp 1-50 in The Optimum Quantity of Money and Other Essays.Chicago: Aldine Publishing Company.

Galì, Jordi and Mark L.Gertler. 1999. "Inflation Dynamics: a Structural Econometric Approach." Journal of Monetary Economics 44:195-222. http://dx.doi.org/10.1016/S0304-3932(99)00023-9

Krugman, Paul R. 1998. "It's Baaack: Japan's Slump and the Return of the Liquidity Trap" Brookings Papers on Economic Activity 29:137-206. http://dx.doi.org/10.2307/2534694

Kydland, Finn E. and Edward C. Prescott. 1977. "Rules rather than Discretion: the Inconsistency of Optimal Plans." Journal of Political Economy 85:473-491. http://dx.doi.org/10.1086/260580

Levin, Andrew T., David Lopez-Salido, Edward Nelson and Tack Yun. 2008. "Macroeconometric Equivalence, Microeconomic Dissonance, and the Design of Monetary Policy." Journal of Monetary Economics 55:548-562. http://dx.doi.org/10.1016/j.jmoneco.2008.07.013

Pontiggia, Dario. 2012. "Optimal Long-Run Inflation and the New Keynesian Model." Journal of Macroeconomics 34:10771094. http://dx.doi.org/10.1016/j.jmacro.2012.07.003

Summers, Lawrence H. 1991. "How Should Long-Term Monetary Policy Be Determined? Panel Discussion." Journal of Money, Credit and Banking 23:625-31. http://dx.doi.org/10.2307/1992697

Svensson, Lars E.O. 2003 "Escaping from a Liquidity Trap and Deflation: The Foolproof Way and Others." Journal of Economic Perspectives 17:145-166. http://dx.doi.org/10.1257/089533003772034934

Tobin, James. 1972. "Inflation and Unemployment" American Economic Review 62:1-18.

Walsh, Carl E. 2010. Monetary Theory and Policy. Third Edition. MIT Press Books.

Woodford, Michael. 2003. Interest and Prices: Foundations of a Theory of Monetary Policy. Princeton University Press: Princeton.

Woodford, Michael. 1999. "Commentary: how Should Monetary Policy Be Conducted in an Era of Price Stability?" Pp 277316 in New Challenges for Monetary Policy, Federal Reserve Bank of Kansas City.

\section{DOI: http://dx.doi.org/10.6000/1929-7092.2016.05.21}

(C) 2016 Dario Pontiggia; Licensee Lifescience Global.

This is an open access article licensed under the terms of the Creative Commons Attribution Non-Commercial License (http://creativecommons.org/licenses/by-nc/3.0/) which permits unrestricted, non-commercial use, distribution and reproduction in any medium, provided the work is properly cited. 